\begin{tabular}{|c|l|}
\hline Title & Bronchoscopic microsampling method for measuring drug concentration in epithelial lining fluid \\
\hline Author(s) & Y amazaki, Koichi; Ogura, Shigeaki.; Ishizaka, A kitoshi; Oh-hara, Toshinari; Nishimura, Masaharu \\
\hline Citation & $\begin{array}{l}\text { A merican Journal of Respiratory and Critical Care Medicine, 168(11), 1304.1307 } \\
\text { https://doi.org/10.1164/fccm.200301-1110C }\end{array}$ \\
\hline Issue Date & 2003-12-01 \\
\hline Doc URL & http://hdl.handle.net/2115/17094 \\
\hline Type & article \\
\hline File Information & A JR\&CCM16811.pdf \\
\hline
\end{tabular}

Instructions for use 


\title{
Bronchoscopic Microsampling Method for Measuring Drug Concentration in Epithelial Lining Fluid
}

\author{
Koichi Yamazaki, Shigeaki Ogura, Akitoshi Ishizaka, Toshinari Oh-hara, and Masaharu Nishimura
}

First Department of Medicine, Hokkaido University School of Medicine; Department of Respiratory Disease, Sapporo City General Hospital, Sapporo; Department of Medicine, Tokyo Electric Power Company Hospital, Ibaraki; and Contract Research Department I, ADME/TOX Research Institute, Daiichi Pure Chemicals Co., Ltd., Tokyo, Japan

\begin{abstract}
Direct measurement of the concentration of antimicrobial agents in bronchial epithelial lining fluid (ELF) would allow for a more informed approach to appropriate dosing of antimicrobial agents for respiratory tract infections. In this study, we determined the time versus concentration profile in ELF after an oral administration of levofloxacin, using recently developed bronchoscopic microsampling probes. These probes could be repeatedly and safely inserted through the fiberoptic bronchoscope in normal healthy volunteers. The concentration of levofloxacin in ELF was $43.4 \%$ of the corresponding serum value at $\mathbf{1}$ hour, reached the same level at $\mathbf{2}$ hours, decreased in a similar manner as that in serum, and returned to undetectable levels at $\mathbf{2 4}$ hours. It exceeded minimal inhibitory concentrations of Staphylococcus aureus $(0.25 \mu \mathrm{g} / \mathrm{ml})$, Klebsiella species $(0.5 \mu \mathrm{g} / \mathrm{ml})$, and Haemophilus influenzae $(0.06 \mu \mathrm{g} / \mathrm{ml})$ after 6 hours. The experimental procedure was well tolerated, and no complications were observed. In conclusion, bronchoscopic microsampling is a feasible and promising method for measuring antimicrobial concentrations in the target sites of respiratory tracts directly and repeatedly.
\end{abstract}

Keywords: bronchoscopy; antimicrobial agents; respiratory tract infection; time versus concentration profile; levofloxacin

Community-acquired bacterial pneumonia and ventilatorassociated pneumonia in critically ill patients remain frequent causes of death worldwide (1-3). Although the introduction of recently developed antimicrobial agents has substantially improved the outcome of respiratory tract infections (4), the number of cases in which antimicrobial therapy fails to be effective remains high. Some therapeutic failures are attributed to drugresistant pathogens $(5,6)$. Therapeutic failures may also be related to an inability of antibiotics to penetrate target sites such as bronchoalveolar spaces sufficiently $(7,8)$. Thus, direct measurement of antimicrobial concentrations in bronchoalveolar space fluid may lead to a critical reappraisal of current antimicrobial dosing guidelines (9). To date, drug concentrations at the site of infection in the respiratory tracts of humans have been estimated by assaying whole-lung tissue, collecting sputum or sampling bronchoalveolar lavage (BAL) fluid (10-14). However, at least two methodologic problems hamper a correct interpretation of data derived from these techniques: (1) the concentration in the collected samples might not necessarily reflect the concentration at the anatomic target site, and (2) it would be impossible to obtain samples easily and repeatedly from the same subject. Herkner and colleagues recently introduced flexible microdialysis catheters, which were implanted during lung surgery for

(Received in original form January 28, 2003; accepted in final form August 4, 2003)

Correspondence and requests for reprints should be addressed to Koichi Yamazaki, First Department of Medicine, Hokkaido University School of Medicine, North 15, West 7, Kitaku, Sapporo 060-8638, Japan. E-mail: kyamazak@med.hokudai.ac.jp

This article has an online data supplement, which is accessible from this issue's table of contents online at www.atsjournals.org

Am J Respir Crit Care Med Vol 168. pp 1304-1307, 2003

Originally Published in Press as DOI: 10.1164/rccm.200301-1110C on August 6, 2003

Internet address: www.atsjournals.org pulmonary tumors, to measure the time versus antimicrobial concentration profile in the lung interstitial fluid (15). Although this method allowed for repeated measurements of drug concentrations in lung tissue of patients in vivo, the invasive nature of the procedure would clearly limit clinical use.

We have thus developed a novel approach for measuring drug levels in human bronchial epithelial lining fluid (ELF), a relevant target site for most bacterial infections in vivo. Using bronchoscopy with bronchoscopic microsampling (BMS) probes, we can repeatedly obtain ELF at the target site. To prove the validity of this approach, we determined the time versus concentration profile of a model antibiotic, levofloxacin. The new quinolone was used for this study because the pharmacokinetic properties in serum are well characterized and it is a standard drug for the treatment of respiratory tract infections (16-18).

\section{METHODS}

\section{Subjects}

The study was approved by the institutional ethics committee of Hokkaido University School of Medicine. We recruited 10 healthy men (24-25 years old) with weight ranging from 64 to $82 \mathrm{~kg}$ and height ranging from 168 to $178 \mathrm{~cm}$ and with no recent lung infections. All subjects were provided with detailed descriptions of the study, and written informed consent was obtained.

\section{BMS and BAL under Bronchoscopy}

We have previously described the development of a BMS probe (19). In this study, we used a BMS probe (model BC-402C; Olympus, Tokyo, Japan) that comprised a $2.5-\mathrm{mm}$ outer diameter polyethylene sheath and an inner $1.9-\mathrm{mm}$ polyester fiber rod probe attached to a stainless steel guide wire (Figure 1). This probe immediately adsorbs fluid. In vitro experiments confirmed that adsorption of $1 \mu \mathrm{g} / \mathrm{ml}$ of levofloxacin or $2-20 \mathrm{ml}$ of human serum into the cotton probe allowed for a more than $95 \%$ recovery of biochemical compounds. After each subject was intramuscularly administered with $7.5 \mathrm{mg}$ of pentazocine hydrochloride and local anesthesia of the upper respiratory tracts was achieved with a few milliliters of $2-4 \%$ lidocaine, a flexible fiberoptic bronchoscope (model BF-1T30; Olympus) was inserted into the right lower lobe bronchus. After a channel of the bronchoscope was flushed with air, the BMS probe was inserted through the channel into a segmental bronchus of the right lower lobe bronchus. Then the inner probe was advanced slowly into the distal airway, and sampling of ELF was performed by placing the probe gently at a site of targeted bronchial wall for 10 seconds. The inner probe was withdrawn into the outer tube, and both devices were withdrawn simultaneously. The wet inner probe was sectioned $2 \mathrm{~cm}$ from its tip. Three sectioned probes at one time point from each subject were placed in a preweighed tube and weighed. A dilute solution was prepared by adding $2 \mathrm{ml}$ of saline to the tube and vortexing it for 1 minute. The solution was transferred to a new tube and stored at $-20^{\circ} \mathrm{C}$. The probe was then dried and weighed again to measure the ELF volume recovered. Five subjects orally received $100 \mathrm{mg}$ of levofloxacin (Daiichi Pharmaceutical Co., Tokyo, Japan), and bronchoscopy with BMS probe and venipuncture was performed at 1, 2, 3, 6 and 24 hours after levofloxacin administration to determine the time versus concentration profiles of levofloxacin in the ELF and in the serum. To compare data between BMS and BAL, another group of five subjects underwent BMS and BAL procedures simultaneously at 2 hours after levofloxacin administration. 

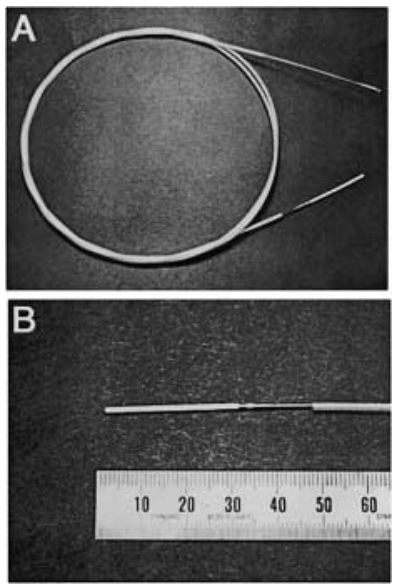

Figure 1. $(A) \mathrm{BMS}$ probe (model $\mathrm{BC}$ 402C; Olympus). (B) A BMS probe comprised a $2.5-\mathrm{mm}$ outer diameter polyethylene sheath and a 1.9-mm inner polyester fiber rod probe attached to a stainless steel guide wire.

\section{Measurement of Levofloxacin and Urea Concentrations} in Serum and in ELF

Levofloxacin concentrations in serum were measured by high-performance liquid chromatography. Levofloxacin concentrations in dilute solutions of ELF were determined by liquid chromatography tandem mass spectrometry. The concentrations of urea in serum and BAL fluid were determined with a commercially available assay kit (Urea Nitrogen Diagnostic Kit, No. 535-A; Sigma-Aldrich Japan, Tokyo, Japan).

\section{Calculations of Levofloxacin Concentration in ELF}

As the ELF sampled by BMS probes was diluted by $2 \mathrm{ml}$ of saline as described previously here, the concentration of levofloxacin in ELF $\left(\mathrm{ABX}_{\mathrm{ELF}}\right)$ was determined as follows:

$$
\mathrm{ABX}_{\mathrm{ELF}}=\mathrm{ABX}_{\mathrm{BMS}} \times(2+\mathrm{ELF} \text { volume }) / \mathrm{ELF} \text { volume }
$$

where $A B X_{B M S}$ is the measured concentration of levofloxacin in the saline-diluted sample.

The calculation of ELF volume and levofloxacin concentrations in ELF sampled by BAL was performed, as previously reported $(13,14,20)$.

\section{Statistical Analysis}

Data were processed with Microsoft Excel and WIN-NONLIN software, and the results are presented as means and SEM (SD).

\section{RESULTS}

There were no adverse events or clinical complications observed while using this procedure. Serum lidocaine concentrations never reached toxic levels $(3 \mu \mathrm{g} / \mathrm{ml})(21,22)$. The mean ELF volume \pm $\mathrm{SD}$ recovered by the BMS probe was $23.3 \pm 24.1 \mu \mathrm{l}$ at one point from three sectioned probes. As samples were diluted by $2 \mathrm{ml}$ of saline, the average dilution factor \pm SD was $134 \pm 70$. We successfully measured the concentration of drug in all of the samples obtained for 6 hours after the subjects were given levofloxacin. Levofloxacin concentrations in ELF at 2 hours after levofloxacin administration are shown in Table 1, where both measured and corrected data are presented (Table 1). Figure 2 shows that the mean concentration of levofloxacin in serum rose rapidly over 1 hour and then slowly fell. The mean concentration of levofloxacin in ELF rose at a slightly slower rate than that in serum, peaked at 2 hours, and then decreased in a similar manner as that in serum. As a consequence, the concentration of levofloxacin in ELF was $43.4 \%$ of the corresponding serum value at 1 hour, reached the same level at 2 hours, and was undetectable at 24 hours. Key pharmacokinetic characteristics are shown in Table 2. In ELF, the area under the concentration curve was approximately $83 \%$ of that in serum, and the maximum drug concentration was approximately $87 \%$ of that in serum. The time taken to achieve the maximum drug concentration in ELF was twice of the serum.

When the levofloxacin level in ELF was compared with the minimum inhibitory concentration 90 for the potential respiratory pathogens isolated in 1998 in Japan, it exceeded the minimum inhibitory concentration 90 for Staphylococcus aureus $(0.25$ $\mu \mathrm{g} / \mathrm{ml})$, Klebsiella species $(0.5 \mu \mathrm{g} / \mathrm{ml})$, and Haemophilus influenzae $(0.06 \mu \mathrm{g} / \mathrm{ml})$ for 6 hours. However, the level of levofloxacin never exceeded the minimum inhibitory concentration 90 for Streptococcus pneumoniae $(2 \mu \mathrm{g} / \mathrm{ml})$ or the minimum inhibitory concentration 90 for Pseudomonas aeruginosa (16 $\mu \mathrm{g} / \mathrm{ml})(23)$.

Finally, we compared the levofloxacin concentrations in ELF calculated using the BMS method with those calculated from BAL fluids at 2 hours after levofloxacin administration. Levofloxacin concentrations in ELF calculated from BAL fluids were approximately twice as high as those calculated using the BMS method $(1.41 \pm 0.32$ vs. $0.71 \pm 0.20 \mu \mathrm{g} / \mathrm{ml}$, respectively, $\mathrm{n}=5$ for each).

\section{DISCUSSION}

With a few notable exceptions such as anticoagulant drugs, most drugs do not exert their effects within the serum compartment but exert their effects in defined target tissues into which drugs have to distribute from the central compartment. However, drug concentrations in defined target tissues are not usually examined by regulatory agencies during drug development.

In this study, we used BMS probes under bronchoscopy to determine the time versus antimicrobial concentration profile in ELF at the target site of respiratory infection. At one time point,

TABLE 1. AN EXAMPLE OF CALCULATION OF LEVOFLOXACIN CONCENTRATION IN EPITHELIAL LINING FLUID USING BRONCHOSCOPIC MICROSAMPLING METHOD (2 HOURS AFTER LEVOFLOXACIN ADMINISTRATION)

\begin{tabular}{|c|c|c|c|c|}
\hline \multirow[b]{2}{*}{ Case } & \multirow[b]{2}{*}{ ELF Volume $(\mu /)^{*}$} & \multirow[b]{2}{*}{ Dilution Factor ${ }^{\dagger}$} & \multicolumn{2}{|c|}{ Levofloxacin Concentration $(\mathrm{ng} / \mathrm{ml})$} \\
\hline & & & Measured Concentration & Corrected Concentration ${ }^{\S}$ \\
\hline 1 & 13.6 & 147 & 9.50 & 1398 \\
\hline 2 & 7.1 & 282 & 5.52 & 1554 \\
\hline 3 & 12.2 & 170 & 4.98 & 817 \\
\hline 4 & 20.3 & 99 & 5.16 & 509 \\
\hline 5 & 26.6 & 75 & 5.81 & 437 \\
\hline
\end{tabular}

Definition of abbreviations: BMS = bronchoscopic microsampling; ELF = epithelial lining fluid

* The ELF volume recovered by three sectioned BMS probes at one time point ( 2 hours after levofloxacin administration).

${ }^{\dagger}$ A diluted solution was prepared by adding $2 \mathrm{ml}$ of saline to the tube.

\# The concentration of levofloxacin in the saline diluted ELF was determined by liquid chromatography/tandem mass spectrometry.

$\S$ The concentration of levofloxacin in each ELF was corrected by each dilution factor. 


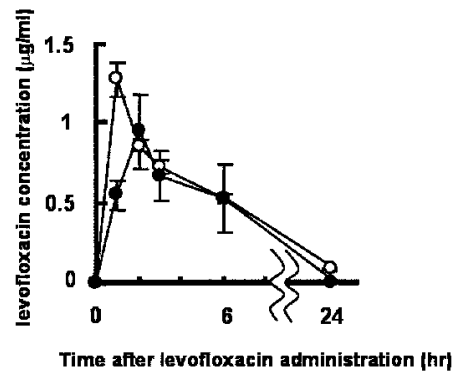

Figure 2. The mean concentration versus time profiles in serum (open circles) and in epithelial lining fluid (closed circles) of levofloxacin after a single oral dose administration of $100 \mathrm{mg}$ of levofloxacin to normal healthy volunteers $(n=5$; data are presented as means \pm SEM).

only a few minutes were required to obtain ELF using the flexible bronchoscope with BMS probes. Local anesthesia of the upper respiratory tracts with a few milliliters of lidocaine alone was sufficient for each bronchoscopic procedure, and bronchoscopy with BMS probes could be repeated without any complications every hour for the first 3 hours. Moreover, we were able to obtain sufficient amounts of ELF to measure levofloxacin concentrations by introducing three sectioned BMS probes into the tube at one time. Although the concentration in the saline diluted ELF samples could not be measured by high-performance liquid chromatography, in contrast to that in the serum samples, liquid chromatography tandem mass spectrometry facilitated measurement of lower levofloxacin concentrations in the saline diluted ELF samples.

The levofloxacin concentration in ELF was $43.4 \%$ of the corresponding serum value at 1 hour, matched the serum level at 2 hours, decreased similarly to that in serum, and became undetectable at 24 hours. It is of note that levofloxacin concentrations in ELF never exceeded those in serum at any time point examined. These findings do not agree with previous studies using BAL, in which the concentrations of the levofloxacin in BAL fluid were approximately twice as high as those of plasma for at least 12 hours $(13,14)$. Although BAL has been considered to be only way of obtaining ELF from humans, this method includes a substantial methodologic problem (24). Accurate quantification of ELF volume recovered by BAL is impractical. Urea has been used as an endogenous marker of ELF because urea is a small, relatively nonpolar molecule that travels across membranes freely and has been thought to exist at the same concentration in ELF as it does in the blood $(13,14)$. However, it has also been shown that during prolonged BAL exposure, urea diffuses from the interstinum and blood and therefore falsely elevates the urea concentration in BAL fluid (25). Therefore, the BMS method, which does not include urea concentration, is thought to be a more reliable method for measuring drug concentrations in ELF. Indeed, our data for comparison between BMS and BAL demonstrate that drug concentrations determined using the two methods are significantly different. However, such differences may not be explained exclusively by

TABLE 2. KEY PHARMACOKINETIC PARAMETERS OF LEVOFLOXACIN IN SERUM AND EPITHELIAL LINING FLUID

\begin{tabular}{lcc}
\hline & Serum & Epithelial Lining Fluid \\
\hline $\mathrm{AUC}(\mu \mathrm{g} \cdot(\mathrm{hr} / \mathrm{ml})$ & $4.34 \pm 0.51$ & $3.62 \pm 1.60$ \\
$\mathrm{Cmax}(\mu \mathrm{g} / \mathrm{ml})$ & $1.27 \pm 0.24$ & $1.11 \pm 0.34$ \\
$\mathrm{Tmax}(\mathrm{hr})$ & $1.0 \pm 0$ & $2.0 \pm 0.7$ \\
\hline
\end{tabular}

Definition of abbreviations: $\mathrm{AUC}=$ area under the concentration curve from 0 to 240 minutes; $\mathrm{Cmax}=$ maximum drug concentration; $\mathrm{Tmax}=$ time to maximum drug concentration.

Data are presented as means \pm SD. method-oriented error. BAL mainly samples ELF of the alveolar space, whereas BMS samples ELF of the bronchial space.

In conclusion, BMS using bronchoscopy is a feasible and promising method for measuring antimicrobial concentrations in the respiratory tracts directly and repeatedly. Further investigations into other antimicrobial concentrations in ELF, in various clinical settings, using the BMS method may lead to a critical reappraisal of current antimicrobial dosing guidelines. The data obtained in this study also support the use of levofloxacin for treatment of respiratory tract infections with most bacterial species.

Conflict of Interest Statement: K.Y. has no declared conflict of interest; S.O. has no declared conflict of interest; A.I. has no declared conflict of interest; T.O-h. has no declared conflict of interest; M.N. has no declared conflict of interest.

Acknowledgment: The authors thank Dr. Ichiro Kinoshita and Dr. Etsuro Yamaguchi of the First Department of Medicine at the Hokkaido University School of Medicine and Dr. Hirotoshi Dosaka-Akita of the Department of Medical Oncology at the Hokkaido University Graduate School of Medicine, Sapporo, Japan, for assistance.

\section{References}

1. Bartlett JG, Mundy LM. Community-acquired pneumonia. $N$ Engl J Med 1995;333:1618-1624

2. Kaplan V, Angus DC, Griffin MF, Clermont G, Scott WR, Linde-Zwirble WT. Hospitalized community-acquired pneumonia in the elderly: ageand sex-related patterns of care and outcome in the United States. Am J Respir Crit Care Med 2002;165:766-772.

3. Rello J, Torres A, Ricart M, Valles J, Gonzalez J, Artigas A, RodriguezRoisin R. Ventilator associated pneumonia by Staphylococcus aureus comparison of methicillin-resistant and methicillin-sensitive episodes. Am J Respir Crit Care Med 1994;150:1545-1549.

4. Bullowa JGM. The reliability of sputum typing and its relation to serum therapy. JAMA 1935;105:1512-1518.

5. El Solh AA, Aquilina AT, Dhillon RS, Ramadan F, Nowak P, Davies J. Impact of invasive strategy on management of antimicrobial treatment failure in institutionalized older people with severe pneumonia. Am J Respir Crit Care Med 2002;166:1038-1043.

6. Davidson R, Cavalcanti R, Brunton JL, Bast DJ, de Azavedo JCS, Kibsey P, Fleming C, Low DE. Resistance to levofloxacin and failure of treatment of pneumococcal pneumonia. N Engl J Med 2002;346:747-750.

7. Brunner M, Pernerstorfer T, Mayer BX, Eichler HG, Muller M. Surgery and intensive care procedures affect the target site distribution of piperacillin. Crit Care Med 2000;28:1754-1759.

8. Joukhadar C, Frossard M, Mayer BX, Brunner M, Klein N, Siostrzonek P, Eichler HG, Müller M. Impaired target site penetration of betalactams may account for therapeutic failure in patients with septic shock. Crit Care Med 2001;29:385-391.

9. Niederman MS, Mandell LA, Anzueto A, Bass JB, Broughton WA, Campbell GD, Dean N, File T, Fine MJ, Gross PA, et al. Guidelines for the management of adults with community-acquired pneumonia: diagnosis, assessment of severity, antimicrobial therapy, and prevention. Am J Respir Crit Care Med 2001;163:1730-1754.

10. Kiss IJ, Farago E, Pinter J. Serum and lung tissue levels of cephradine in thoracic surgery. Br J Clin Pharmacol 1976;3:891-895.

11. Lee LJ, Sha X, Gotfried MH, Howard JR, Dix RK, Fish DN. Penetration of levofloxacin into lung tissue after oral administration to subjects undergoing lung biopsy or lobectomy. Pharmacotherapy 1998;18:35-41.

12. Chastre J, Brun P, Foutillan JB, Soler P, Basset G, Manuel C, Trouillet JL, Gibert C. Pulmonary disposition of roxitromycin (RU 29865), a new macrolide antibiotic. Antimicrob Agents Chemother 1987:31:1312-1316.

13. Gotfried MH, Danziger LH, Rodvold KA. Steady-state plasma and intrapulmonary concentrations of levofloxacin and ciprofloxacin in healthy adult subjects. Chest 2001;119:1114-1122.

14. Andrews JM, Honeybourne D, Jevons G, Brenwald NP, Cunningham B, Wise R. Concentrations of levofloxacin (HR 355) in the respiratory tract following a single oral dose in patients undergoing fibre-optic bronchoscopy. J Antimicrob Chemother 1997:40:573-577.

15. Herkner H, Muller MR, Kreischitz N, Mayer BX, Frossard M, Joukhadar C, Klein N, Lackner E, Muller M. Closed-chest microdialysis to measure antibiotic penetration into human lung tissue. Am J Respir Crit Care Med 2002:165:273-276.

16. Marrie TJ, Lau CY, Wheeler SL, Wong CJ, Vandervoort MK, Feagan BG. A controlled trial of a critical pathway for treatment of communityacquired pneumonia: CAPITAL Study Investigators: community-ac- 
quired pneumonia intervention trial assessing levofloxacin. JAMA 2000;283:749-755.

17. Preston SL, Drusano GL, Berman AL, Fowler CL, Chow AT, Dornseif B, Reichl V, Natarajan J, Corrado M. Pharmacodynamics of levofloxacin: a new paradigm for early clinical trials. JAMA 1998;279:125-129.

18. Tanigawara Y, Nomura H, Kagimoto N, Okumura K, Hori R. Premarketing population pharmacokinetic study of levofloxacin in normal subjects and patients with infectious diseases. Biol Pharm Bull 1995; $18: 315-320$

19. Ishizaka A, Watanabe M, Yamashita T, Ogawa Y, Koh H, Hasegawa N, Nakamura H, Asano K, Yamaguchi K, Kotani M, et al. New bronchoscopic microsample probe to measure the biochemical constituents in epithelial lining fluid of patients with acute respiratory distress syndrome. Crit Care Med 2001;29:896-898.

20. Baldwin DR, Wise R, Andrews JM, Ashby JP, Honeybourne D. Azithromycin concentrations at the sites of pulmonary infection. Eur Respir J 1990;3:886-890.
21. Bromage PR, Robson JG. Concentrations of lignocaine in the blood after intravenous, intramuscular, epidural and endotracheal administration. Anaesthesia 1961;16:461-478.

22. Scott DB. Evaluation of clinical tolerance of local anaesthetic agents Br J Anaesth 1975;47:328-331.

23. Yamaguchi K, Miyazaki S, Kashitani F, Iwata M, Kanda M, Tsujio Y, Okada J, Tazawa Y, Watanabe N, Uehara N, et al. Activities of antimicrobial agents against 5,180 clinical isolates obtained from 26 medical institutions during 1998 in Japan: Levofloxacin-Surveillance Group. Jpn J Antibiot 2000;53:387-408.

24. Baldwin DR, Honeybourne D, Wise R. Pulmonary disposition of antimicrobial agents: methodological considerations. Antimicrob Agents Chemother 1992:36:1171-1175.

25. Rennard SI, Basset G, Lecossier D, O’Donnell KM, Pinkston P, Martin PG, Crystal RG. Estimation of volume of epithelial lining fluid recovered by lavage using urea as marker of dilution. J Appl Physiol 1986; 60:532-538. 